\title{
Involvement of Amygdala Dopamine and Nucleus Accumbens NMDA Receptors in Ethanol-Seeking Behavior in Mice
}

\author{
Christina M Gremel*,' and Christopher L Cunningham' \\ 'Department of Behavioral Neuroscience, Portland Alcohol Research Center, Oregon Health \& Science University, Portland, OR, USA
}

\begin{abstract}
Although progress has been made identifying neural mechanisms underlying ethanol's primary reinforcing effects, few studies have examined the mechanisms mediating ethanol-induced conditioned effects. A recent lesion study suggests that expression of ethanolconditioned behaviors depends upon an intact amygdala and nucleus accumbens core. However, specific mechanisms within these nuclei are unknown. In the present experiments, we used site-specific microinfusions of dopamine and NMDA receptor antagonists to examine the roles of accumbens and amygdala in the expression of ethanol conditioned place preference (CPP) in mice. In experiments I and 2, a DI/D2/D3 receptor antagonist (flupenthixol) was infused into accumbens or amygdala before testing, whereas experiment 3 used pretest infusions of an NMDA antagonist (AP-5) to examine the role of intra-accumbens NMDA receptors. Dopamine antagonism of accumbens was without effect, but intra-amygdala infusions of flupenthixol blocked CPP expression. Moreover, this effect was dependent upon dopamine antagonism within the basolateral nucleus but not the central nucleus of the amygdala. Antagonism of NMDA receptors in accumbens also blocked CPP expression. The present findings suggest that expression of the ethanol-conditioned response depends upon amygdala dopamine and accumbens NMDA receptors. These are the first studies in any species to show a role for amygdala dopamine receptors and the first studies in mice to implicate accumbens NMDA receptors in ethanol-induced conditioned effects. Neuropsychopharmacology (2009) 34, I443- |453; doi: 10. I038/npp.2008. 179; published online I October 2008
\end{abstract}

Keywords: ethanol; conditioned place preference; basolateral amygdala; nucleus accumbens; NMDA receptor; dopamine receptor

\section{INTRODUCTION}

Although alcohol abuse and dependence are widespread, knowledge about the neurobiological mechanisms regulating ethanol-seeking behaviors is limited. Conditioned responses to environmental stimuli predictive of ethanol's effects are thought to be critical for instigating ethanolseeking behaviors and maintaining ethanol consumption. Understanding the neural mechanisms of cue-induced ethanol seeking may offer insight into reducing the physiological/behavioral responses, motivational states, or expectancies that lead to craving and relapse (Corbit and Janak, 2007; Cunningham, 1994, 1998; Krank, 1989, 2003).

Most studies of the neural mechanisms involved in ethanol seeking have used rats trained in operant oral self-administration (SA) procedures. Such studies have suggested roles for dopamine D2 (Samson et al, 1993; Hodge et al, 1997) and N-methyl-D-aspartic (NMDA) (Rassnick et al, 1992) receptors within the nucleus accumbens (Acb) and for $\mathrm{GABA}_{\mathrm{A}}$ (Hyytiä and Koob,

\footnotetext{
*Correspondence: Dr CM Gremel, Section on In Vivo Neural Function, Laboratory for Integrative Neuroscience, NIAAA/NIH 5625 Fishers Lane, Room TS-20, Rockville, MD 20852, USA, Tel: + I 30I 4434228 , Fax: + I 301480 0466, E-mail: gremelc@mail.nih.gov

Received 23 May 2008; revised 6 September 2008; accepted 8 September 2008
}

1995) and opioid (Heyser et al, 1999) receptors within the central nucleus (CE) of the amygdala (Amy). Although some studies have suggested that dopamine receptors within Acb play a greater role in mediating ethanol conditioned appetitive responses than in mediating ethanol consumption (Czachowski et al, 2001, 2002; Samson and Chappell, 2004), most SA studies have failed to distinguish between the mechanisms underlying ethanol's primary reinforcing effects and those underlying ethanol-induced conditioned reinforcing or conditioned motivational effects.

In contrast to SA, the conditioned place preference (CPP) procedure is well suited for studying the acquisition and expression of conditioned motivational and/or conditioned reinforcing effects of abused drugs (Tzschentke, 2007), as multiple associative processes may influence the approach behavior to the previously drug-paired cue including Pavlovian approach behavior, conditioned reinforcement, and incentive motivational processes (Cunningham et al, 2006a; Robbins and Everitt, 2002; Uslaner et al, 2006). Further, one can examine pretreatment drug effects on CPP expression in the absence of the training drug (Cunningham et al, 2006a), which provides a means to investigate the neurobiological mechanisms of associative processes that influence drug conditioned behaviors. Although two recent rat studies have suggested roles for dopamine receptors in the Acb shell (Walker and Ettenberg, 2007) and for NMDA receptors in the CE (Zhu et al, 2007) on ethanol CPP 
expression, interpretation of these studies is complicated because most rat studies have reported no conditioning or conditioned place aversion with ethanol (Tzschentke, 1999, 2007; Fidler et al, 2004). In contrast, ethanol CPP is reliably observed in mice (Cunningham et al, 2006a; Tzschentke, 1999, 2007). Using this model, a previous study showed that opioid and $\mathrm{GABA}_{\mathrm{B}}$ receptors within the ventral tegmental area (VTA) mediated expression of ethanol CPP whereas blocking opioid receptors in the Acb had no effect (Bechtholt and Cunningham, 2005). Moreover, a recent lesion study in mice identified functional roles for both the Acb and Amy in ethanol CPP (Gremel and Cunningham, 2008). However, the specific neural mechanisms in the Acb and Amy that modulate ethanol CPP in mice are unknown.

Since the VTA sends dopaminergic afferents to the Acb and Amy (Swanson, 1982; Ford et al, 2006), it may be that expression of ethanol CPP depends on dopamine receptor activation in these areas. However, the Amy also directly innervates the Acb through basolateral amgydala (BLA) glutamate afferents (Groenewegen et al, 1996). This connection raises the possibility that recruitment of $\mathrm{Acb}$ activity during expression of ethanol-conditioned behaviors may depend upon glutamate input from the Amy or alternatively, other cortical sources (Sesack et al, 1989, 1990; Totterdell and Smith, 1989). Indeed, previous findings suggest that blockade of NMDA receptors in the Acb decreases ethanol reinforced behavior (Rassnick et al, 1992).

To determine whether specific receptors within the Acb or Amy modulate the conditioned motivational/conditioned reinforcing effects of ethanol, we used site-specific bilateral infusions of a D1/D2/D3 receptor antagonist (into the Acb or Amy) or an NMDA receptor antagonist (into the Acb) to assess the influence of these receptors on expression of ethanol CPP in mice. These are the first studies in any species to evaluate the role of Amy dopamine receptors and the first studies in mice to assess the roles of Acb dopamine and NMDA receptors in ethanol's conditioned motivational/ conditioned reinforcing effects.

\section{MATERIALS AND METHODS}

\section{Subjects}

Male DBA/2J $(n=500)$ mice were obtained from the Jackson Laboratory (Bar Harbor, ME or Davis, CA) at 6-7 weeks of age. Animals were initially housed in groups of four on a Thoren rack (Thoren Caging Systems Inc., Hazleton, PA) in polycarbonate cages. After surgical procedures, animals were housed two per cage for the duration of the experiments. Animals were kept at an ambient temperature of $21 \pm 1^{\circ} \mathrm{C}$ on a 12-h light-dark cycle (lights on at 0700 hours). Experiments were carried out during the light portion of the cycle beginning at $1300 \mathrm{~h}$. 'Labdiet' rodent chow (Richmond, IN) and bottled water were continuously available in the home cage. The National Institutes of Health (NIH) 'Principles of Laboratory Animal Care' were followed in conducting these studies and the protocol was approved by the Oregon Health \& Science University IACUC.

\section{Surgery}

Mice were fully anesthetized with a cocktail ( $0.1 \mathrm{ml}$ per $25 \mathrm{~g})$ containing ketamine $(30.0 \mathrm{mg} / \mathrm{ml})$ and xylazine $(3.0 \mathrm{mg} / \mathrm{ml})$. Bilateral indwelling cannulae were implanted under stereotaxic guidance (model no. 1900; Kopf Instruments, Tujunga, $\mathrm{CA}$ ) aimed at the nucleus accumbens core (AcbC) (from Bregma: anterior $(\mathrm{AP})+1.40$, lateral $(\mathrm{ML}) \pm 1.26$, ventral (DV) -4.2 ) or basolateral/central nuclei of the amygdala (BLA/CE) (from Bregma: AP, 1.22, ML, $\pm 2.85, \mathrm{DV}, 4.5$; Paxinos and Franklin, 2001). Small burr holes were drilled and stainless steel cannulae $(10 \mathrm{~mm}, 25$ gauge $)$ were positioned $2 \mathrm{~mm}$ above the target area (experiments 1,2, and 3). Cannulae were secured with stainless steel screws and carboxylate cement (Durelon ${ }^{\mathrm{TM}} ; 3 \mathrm{M}$, St Paul, MN). Thirty-two gauge stainless steel stylets were inserted into the length of each guide cannula to maintain patency. To control for possible effects of recovery time (4-9 days), the number of recovery days was counterbalanced across infusion groups.

\section{Apparatus}

A detailed description and picture of the apparatus has been published (Cunningham et al, 2006a). Conditioned stimuli (CSs) consisted of two interchangeable distinctive grid and hole floor halves (for a more detailed description see Cunningham et al, 2006a) that were selected on the basis of many previous studies demonstrating that drug-naïve control DBA/2J mice spend about half of their time on each floor type during choice tests (Cunningham et al, 2003; Gremel and Cunningham, 2008).

\section{Conditioning Drugs}

Ethanol (95\%) was diluted in $0.9 \%$ saline $(20 \%, \mathrm{v} / \mathrm{v})$ and administered at a dose of $2 \mathrm{~g} / \mathrm{kg}(12.5 \mathrm{ml} / \mathrm{kg})$. In previous experiments, this ethanol dose and concentration has reliably induced a strong CPP in DBA/2J mice (Cunningham et al, 2003). Saline was administered in a volume of $12.5 \mathrm{ml} / \mathrm{kg}$.

\section{General Procedure}

Each experiment involved three phases: habituation (1 session), conditioning (8 sessions), and testing (1 session). Each animal was given an intraperitoneal (i.p.) injection immediately before being placed in the center of the apparatus for each session. Sessions were conducted on consecutive days with a 72-h break between the first four and last four conditioning sessions and a 48 -h break before the preference test.

Habituation. On the first day, subjects in all experiments underwent a 5-min habituation trial where they were given an injection of saline and exposed to the apparatus on a smooth paper floor to reduce the novelty and stress associated with handling, injection and exposure to the apparatus.

Conditioning. Mice were randomly assigned to an infusion group described separately for each experiment in a later 
section (Intracranial Microinfusions). Within each infusion group, mice were also randomly assigned to one of two conditioning subgroups (Grid + or Grid-) using an unbiased, one-compartment procedure (Cunningham et al, 2003, 2006a). Conditioning trials were $5 \mathrm{~min}$ in duration because this duration has been shown to be optimal for producing robust ethanol-induced $\mathrm{CPP}$ in DBA/2J mice (Cunningham and Prather, 1992). Both subgroups were exposed to a differential Pavlovian conditioning procedure in which they received four CS + and four CS - trials, alternating across 8 days, with the presentation order of CS + and CS - trials counterbalanced within each group. Mice in the Grid + condition received ethanol paired with the grid floor $(C S+)$ and saline paired with the hole floor (CS-). Mice in the Grid - condition received ethanol paired with the hole floor (CS +) and saline paired with the grid floor (CS-).

Place preference test. Testing began $48 \mathrm{~h}$ after the last conditioning trial for all animals. In each test session mice were first given an intracranial infusion (see next section for details), followed by a test session lasting $30 \mathrm{~min}$ in duration in order to examine any drug effects on the development of CPP across the test session (Cunningham et al, 1995). Immediately after the infusion, mice were given an i.p. saline injection and placed in the center of the apparatus with both test floors (half grid/half hole). Position (ie, left $v s$ right) of each floor type was counterbalanced within subgroups.

\section{Intracranial Microinfusions}

All mice received an intracranial microinfusion immediately before testing (Table 1). At $24 \mathrm{~h}$ before intracranial infusions, a $12 \mathrm{~mm}$ stylet was lowered into the infusion site to minimize possible effects of initial injector lowering on the behavior measured. For microinfusions, mice were gently restrained, stylets were removed and injectors made of 32-gauge stainless steel tubing encased by 25-gauge stainless steel were lowered beyond the tip of the guide cannula into the Amy or Acb. Injectors were attached via polyethylene tubing (PE20) to $10 \mu$ Hamilton syringes, and infusions were delivered by a syringe pump (Model A-74900-10; Cole Palmer, Vernon Hills, IL). Simultaneous infusions of $100 \mathrm{nl}$ per side were given over $60 \mathrm{~s}$ to limit injection spread into neighboring brain areas, as well as to minimize diffusion up the injector track. Further, to ensure complete diffusion, injectors were removed $30 \mathrm{~s}$ after completion of the infusion and stylets were replaced.
To examine the role of intra-Acb and intra-Amy dopamine receptors in the expression of ethanol CPP, in experiments 1 (six replications) and 2 (4 replications), the mixed D1/D2/D3 dopamine receptor antagonist cis-(Z)flupenthixol dihydrochloride (flupenthixol) obtained from Sigma-Aldrich (St Louis, MO) was infused into the AcbC (artificial cerebrospinal fluid (aCSF), 1, 10, or $20 \mu \mathrm{g}$ per side) or Amy (aCSF, 10, or $20 \mu \mathrm{g}$ per side). To examine the contribution of intra-Acb NMDA receptors, in experiment 3 (two replications), mice were given infusions of the NMDA receptor antagonist D-(-)-2-amino-5-phosphonopentanoic acid (AP-5) (Ascent Scientific, Weston-Super-Mare, UK; Tocris, Ellsville, MO) into the AcbC (aCSF, 0.5 , or $1.0 \mu \mathrm{g}$ per side). All drugs were dissolved in aCSF.

\section{Histology}

Animals were given an overdose of sodium pentobarbital $(150 \mathrm{mg} / \mathrm{kg})$. Heads were removed and postfixed in $4 \%$ (w/v) paraformaldehyde in isotonic sodium phosphate buffered saline (PBS). After $24 \mathrm{~h}$, brains were dissected from the skull and placed into a solution of $2 \%$ paraformaldehyde for $24 \mathrm{~h}$. After fixation, brains were cryoprotected using a sucrose saturation procedure consisting of $24 \mathrm{~h}$ incubations in $20 \%$ and then $30 \%$ sucrose in PBS and $0.1 \% \mathrm{NaN}_{3}$. Frozen $40 \mu \mathrm{m}$ sections were collected through the infusion site. Slices were directly mounted onto slides and thionen stained.

Placements were subjectively assessed blind to dose, conditioning subgroup, and test outcome. Inclusion criteria were as follows: subjects with bilateral injector tracks within AcbC were included in analyses in experiments 1 and 3 . Although inclusion criteria specified injector tracks within $\mathrm{AcbC}$, given the close proximity and possibility of drug diffusion into the nucleus accumbens shell (AcbSh) and the lack of a sufficient number of subjects with injector tracks localized solely in the AcbSh as a site-comparison group, we present results as infusions in Acb and do not make $\mathrm{AcbC} /$ AcbSh distinction. In experiment 2, subjects with bilateral injector tracks located within BLA and/or CE were included in analyses.

\section{Data Analyses}

For data analysis, number of seconds spent on the grid floor was divided by total duration of the test session in minutes (ie, 30), creating a dependent variable indexed in $\mathrm{s} / \mathrm{min}$. The

Table I Subject Removal

\begin{tabular}{|c|c|c|c|c|c|c|c|}
\hline & Initial (n) & Final (n) & Surgery and recovery & Procedural error & Histology error & Miss & Infection \\
\hline \multicolumn{8}{|l|}{ Experiment I } \\
\hline Intra-Acb flupenthixol & 216 & 109 & 6 & 3 & 8 & 39 & 51 \\
\hline \multicolumn{8}{|l|}{ Experiment 2} \\
\hline Intra-Amy flupenthixol & 190 & 74 & 36 & 4 & 7 & 50 & 19 \\
\hline Intra-Acb AP-5 & 94 & 63 & - & 4 & 2 & 7 & 18 \\
\hline
\end{tabular}


primary advantage of this simple transformation is that results are easily compared with the full range of possible outcomes (eg, $0 \mathrm{~s} / \mathrm{min}=$ complete aversion to grid; $60 \mathrm{~s} /$ $\min =$ complete preference for grid). Also, because there are only two floors, the amount of time spent on the hole floor can be determined simply by subtracting the mean time on grid from $60 \mathrm{~s}$. In this unbiased design, the between-group comparison of time spent on the grid floor by the Grid + and Grid- conditioning subgroups is indicative of CPP. See Cunningham et al (2003) for a more complete discussion of dependent variables used in place conditioning studies. Data from each experiment were evaluated separately by analysis of variance (ANOVA) with the $\alpha$-level set at 0.05 . Dose, conditioning subgroup (Grid $+v s$ Grid-), Replication, and Amy site, were treated as between-group factors, whereas trial type (CS $+v s \mathrm{CS}-)$ was treated as a withinsubject factor. Follow-up analyses to interpret interactions involving the Conditioning subgroup variable included simple effect comparisons between the Grid + and Gridsubgroups to determine the presence of place conditioning. To control overall $\alpha$-level within each experiment, $p$-values for these comparisons were Bonferroni-corrected. Dose $\times$ conditioning subgroup interactions were further interpreted by conducting separate two-way ANOVAs for specific pairs of doses using an $\alpha$ of 0.05 .

\section{RESULTS}

\section{Histological Verification and Subject Removal}

Schematic diagrams of inclusion criteria and representative photomicrographs are shown in Figure 1. Subjects were removed from the final analyses for various reasons, including: poor health during recovery following surgical procedures (surgery and recovery), procedural errors during conditioning and testing (procedural error), an inability to accurately assign injector placement due to problems with histological assessment (histology error), incorrect injector placement (miss), or any infection at the injector and/or cannula site (infection) (Table 1). In experiment 1 , and to a lesser degree in experiments 2 and 3 , a relatively large percentage of mice had infections located near the end of the cannula. Although the causes are unknown, this higher rate of infection may have been due to a longer delay and additional microinfusions between the first microinfusion and brain removal. In experiment 1 , brains were removed after all mice had received three microinfusion tests at 24-h intervals (only data from the first test are reported here). In experiments 2 and 3 , however, about half of the brains were removed immediately after the first test whereas the others were removed after only one additional test. In addition, there was no effect of drug-infusion $v s$ aCSF infusion on the proportion of mice with infections. In later experiments (not reported here) where all brains were removed immediately after testing, we observed a very low rate of infection, suggesting that infections observed in the current experiments are the result of multiple intracranial infusions into the mouse brain.

In addition, many mice in experiment 2 were lost during surgical recovery (Table 1). We previously reported significantly larger losses during recovery in mice with bilateral electrolytic lesions of the Amy in comparison to mice with Acb lesions (Gremel and Cunningham, 2008). In the current studies, significantly larger losses were observed during recovery in mice with Amy cannulae than in those
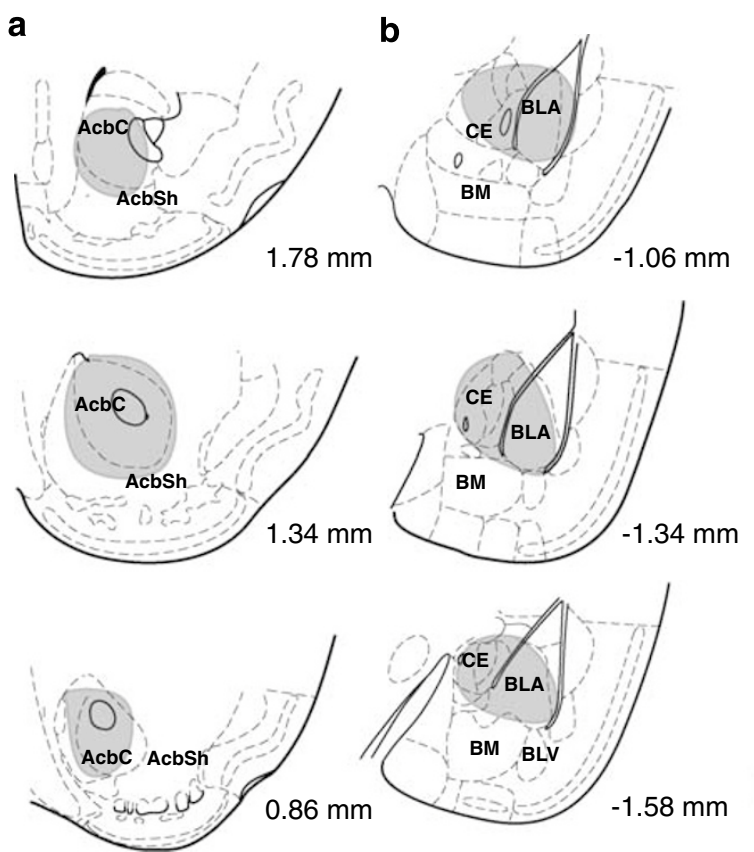

C
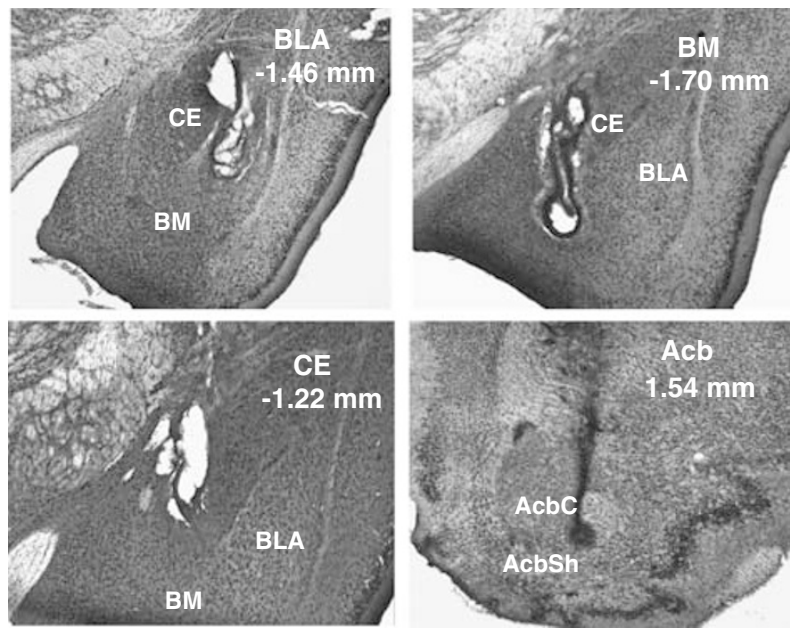

= representation of injector track inclusion area within the Acb (column A) and Amy (column B)

Figure I Representative diagram and photomicrograhs of Acb and Amy injector placements. Representative injector inclusion area criteria are shown for Acb (column a) and Amy (column b). In column c, photomicrographs of representative injector tracks into BLA (upper left panel), CE (lower left panel), BM (upper right panel), and Acb (lower right panel). Photomicrographs are oriented with the medial portion of the brain on the left, and the lateral portion of the right in each photo, and nearby anatomical landmarks are identified. Numbers indicate the distance from bregma in millimeters of the section (Paxinos and Franklin, 200I). 
with Acb cannulae $(z=9.16, p<0.05)$. Because no infusions were made into Amy until testing, it may be that the region just above the Amy in mice is especially sensitive to bilateral cannula insertion.

\section{Place Preference Test}

Experiment 1: effects of intra-Acb dopamine receptor antagonism on CPP expression. In experiment 1, we examined the effect of an intra-Acb flupenthixol infusion $(1,10$, or $20 \mu \mathrm{g}$ per side) on expression of ethanol CPP. In our unbiased design, the magnitude of difference in time spent on the grid floor between Grid + and Gridconditioning subgroups is indicative of CPP. As can be seen in Figure 2, pretreatment with intra-Acb flupenthixol had no impact at any dose, yielding CPP similar to that seen in aCSF control mice. While visual inspection of the data suggests a trend towards enhancement of CPP in the lower dose groups, there were no significant differences between any dose groups. A two-way (dose $\times$ conditioning subgroup) ANOVA revealed a significant main effect of conditioning subgroup (Grid $+v s$ Grid -$)(\mathrm{F}(1,101)=$ 90.0, $p<0.001$ ), but no effect of dose or interaction. Further analysis showed no effect of replication in aCSF control mice $(p>0.05)$ (to create reasonable subgroup $n$ 's for this analysis, data were collapsed across replicates $1-3$, then compared to replicates 4-6). Thus, expression of ethanol CPP did not depend upon D1/D2/D3-type receptor activation in Acb.

Experiment 2: effects of intra-Amy dopamine receptor antagonism on CPP expression. To determine whether dopamine receptor activation in Amy modulated expression of ethanol CPP, mice in experiment 2 were given intra-Amy infusions of flupenthixol immediately before testing. As in

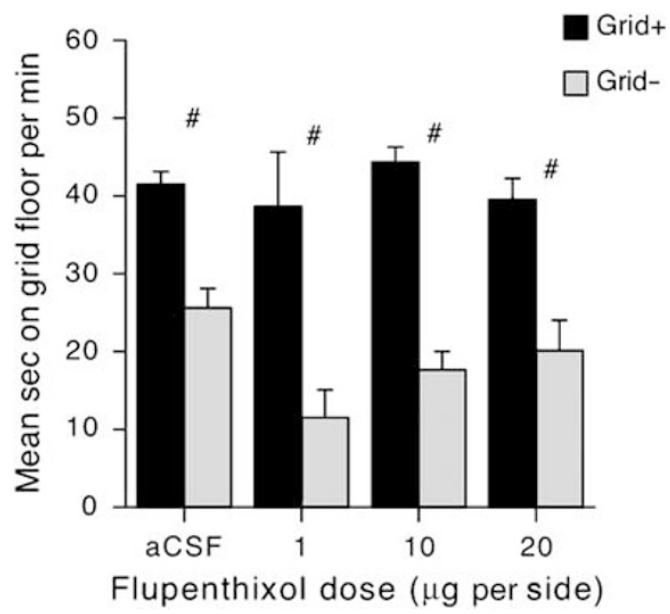

Figure 2 Intra-Acb microinfusions of flupenthixol did not affect expression of ethanol CPP. Mean s/min (+ SEM) spent on the grid floor during the 30-min test session. Subjects in the Grid+ conditioning subgroups (solid bars) received ethanol paired with the grid floor on CS + trials, and saline paired with the hole floor. These contingencies were reversed in the Grid-conditioning subgroup subjects (grey bars). N's for Grid + and Grid-conditioning subgroups are: aCSF $n=28$ and 18; I $\mu \mathrm{g}$ per side $n=5$ and $4 ; 10 \mu$ g per side $n=13$ and 12 , and $20 \mu \mathrm{g}$ per side $n=15$ and 14. Main effect of conditioning between conditioning subgroups is represented by ${ }^{\#}, p<0.001$. experiment 1 , aCSF-treated mice displayed a strong CPP in experiment 2 (Figure 3a). In contrast, intra-Amy flupenthixol infusion disrupted CPP expression at both doses (10 and $20 \mu$ g per side), ie, there was no difference between Grid + and Grid- conditioning subgroups. Further, intra-Amy flupenthixol reduced preference within the first $5 \mathrm{~min}$ and the reduction was observed for the duration of the test session (data not shown). A two-way (dose $\times$ conditioning subgroup) ANOVA revealed a significant main effect of conditioning subgroup (Grid $+v s$ Grid- $)(\mathrm{F}(1,68)=11.8$, $p<0.01)$ and a significant interaction $(\mathrm{F}(2,68)=4.9$, $p<0.05)$. There was no main effect of dose. Post hoc analyses comparing the Grid + and Grid- subgroups showed a significant CPP in the aCSF group (Bonferronicorrected $p<0.001)$, but not in the 10 or $20 \mu \mathrm{g}$ per side dose groups ( $p$ 's $>0.05$ ). To examine whether the magnitude of preference expressed differed between dose groups, follow-up two-way ANOVAs were performed and revealed that preference in the $20 \mu \mathrm{g}$ per side flupenthixol group was significantly lower than that in aCSF control mice (dose $\times$ conditioning subgroup interaction: $\mathrm{F}(1,62)=9.8$, $p<0.01$ ), whereas mice infused with $10 \mu \mathrm{g}$ per side did not differ from either the aCSF or $20 \mu \mathrm{g}$ per side groups $(p$ 's $>0.05)$. A separate analysis performed on data from aCSF-treated mice showed no effect of replication, indicating that preference was similar in the control group across all four replicates. Thus, D1/D2/D3-type receptor antagonism within the Amy blocked ethanol CPP expression.

Experiment 2: differing effects of dopamine receptor antagonism in the BLA or CE on CPP expression. To investigate the contributions of specific nuclei within the Amy on CPP expression, we examined the Amy site of infusion within the $20 \mu \mathrm{g}$ per side flupenthixol dose group (35 mice total). Thus, comparisons were made among subgroups of mice with bilateral infusions of flupenthixol $(20 \mu \mathrm{g}$ per side) into only BLA $(n=14)$, only CE $(n=10)$ or mice with bilateral infusions into both BLA and CE (eg, infusion into BLA in left hemisphere and CE infusions in right hemisphere or infusion tracts in both areas in both hemispheres; Both group, $n=11$ ). Although drug diffusion spread was not specifically examined in these studies, for a site control comparison, these groups were compared to mice with bilateral infusions $(20 \mu \mathrm{g}$ per side) into basomedial amygdala (BM; $n=6)$, which was a common histological miss site.

As shown in Figure 3b, magnitude of ethanol CPP varied between flupenthixol-treated mice depending on Amy site (site $\times$ conditioning subgroup interaction: $\mathrm{F}(3,24)=11.3$, $p<0.001)$. Of particular interest, mice in the BLA and Both groups did not display preference after flupenthixol infusion ( $p$ 's $>0.05)$, whereas subjects with flupenthixol infusions into the CE showed strong ethanol CPP (Bonferroni-corrected $p<0.001)$. Although there was an arithmetic trend toward preference in the BM group, the difference fell short of significance $(p=0.11)$, most likely due to the low $n$ $(n=6)$. Additional two-way (Amy site $\times$ conditioning subgroup) ANOVAs performed between specific pairs of Amy sites did not reveal any differences between CE and BM ( $p$ 's $>0.05)$. However, these analyses showed that the BLA 
a
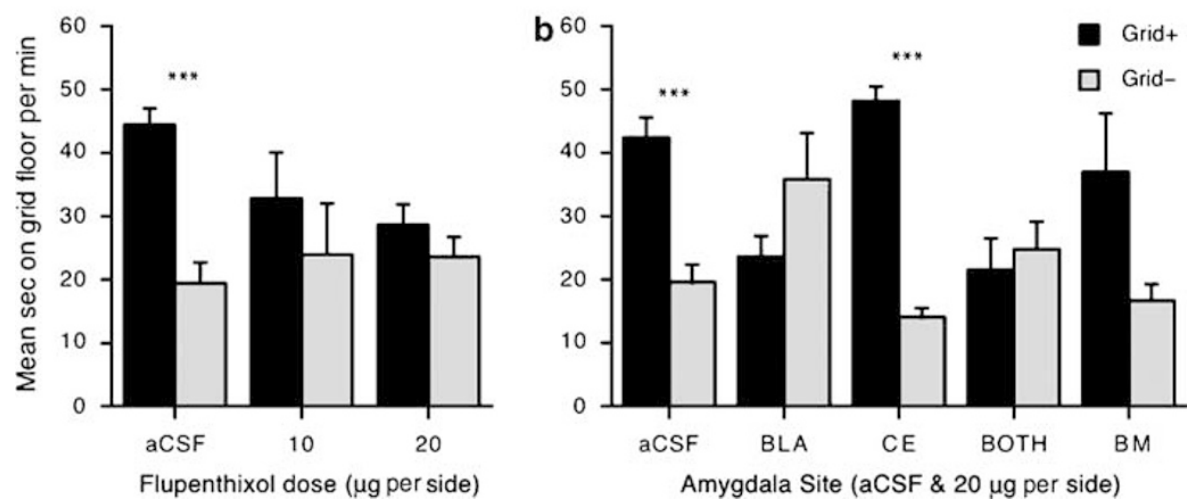

Figure 3 Flupenthixol infused into the Amy disrupts expression of ethanol CPP. Mean s/min ( + SEM) spent on the grid floor during the 30-min test session. (a) Effects of intra-Amy (BLA and CE) infusions of flupenthixol on expression of ethanol CPP. Grid + and Grid- conditioning subgroup n's are: aCSF $n=13$ and 18; $10 \mu \mathrm{g}$ per side $n=4$ and 4; and $20 \mu \mathrm{g}$ per side $n=18$ and 17. (b) Flupenthixol infusions into the BLA, but not CE disrupt expression of ethanol CPP. Test data for aCSF and $20 \mu \mathrm{g}$ per side dose groups grouped by injector site within the Amy, combined with subjects (aCSF and $20 \mu \mathrm{g}$ per side) with injector placements within the BM. Grid + and Grid- conditioning subgroup n's are: aCSF $n=15$ and 22; BLA $n=10$ and 4; CE $n=4$ and 6; Both $n=4$ and 7, and BM $n=3$ and 3. Difference between conditioning subgroups Grid + and Grid-: ***** = Bonferroni-corrected p's $<0.00$ I.

and Both groups each differed significantly from both the $\mathrm{CE}$ and BM groups (F's $>4.7, p$ 's $<0.05$ ). Moreover, the BLA and Both groups did not differ from each other ( $p$ 's $>0.05$ ). Overall, these findings suggest that any D1/D2/D3-type receptor antagonism within the BLA (as evidenced in BLA and Both groups), but not $\mathrm{CE}$, significantly disrupts expression of ethanol CPP. Separate analysis of aCSF control mice showed that CPP did not depend upon site of the aCSF infusion (Amy site $\times$ conditioning subgroup interaction: $\mathrm{F}(3,29)=1.8, p>0.05)$.

Experiment 3: effects of intra-Acb NMDA receptor antagonism on CPP expression. Experiment 3 examined the role of the NMDA receptor in Acb on expression of ethanol CPP. Intra-Acb infusion of the NMDA receptor antagonist AP-5 significantly disrupted CPP expression as shown by the lack of difference between the Grid + and Grid- conditioning subgroups (Figure 4). This disruption was observed within the first $5 \mathrm{~min}$ of the test and lasted the entire session (data not shown). Two-way (dose $x$ conditioning subgroup) ANOVA revealed a significant main effect of conditioning subgroup (Grid $+v s$ Grid-) $(\mathrm{F}(1,57)=36.7, p<0.001)$ and a significant interaction $(\mathrm{F}(2,57)=15.1, p<0.001)$. Post hoc comparisons showed strong ethanol CPP in control (aCSF) mice as indicated by the large difference between the Grid + and Gridconditioning subgroups (Bonferroni-corrected $p<0.001$ ). However, similar comparisons for each AP-5 dose group ( 0.5 or $1.0 \mu \mathrm{g}$ per side) indicated that intra-Acb infusions interfered with expression of ethanol CPP (Bonferronicorrected $p$ 's $>0.05$ ). Follow-up two way ANOVAs showed that although the two AP-5 dose groups did not differ from each other $(p$ 's $>0.05)$, both were significantly different from aCSF controls (dose $\times$ conditioning subgroup interactions: F's $>14.7, p$ 's $<0.001$ ), suggesting that NMDA receptor antagonism in the Acb blocked preference behavior in comparison to aCSF-infused subjects. A separate two-way (replication $\times$ conditioning subgroup) ANOVA showed no effect of replication in aCSF controls. Overall, these findings demonstrate that expression of ethanol CPP is dependent upon NMDA receptor activation within the Acb.

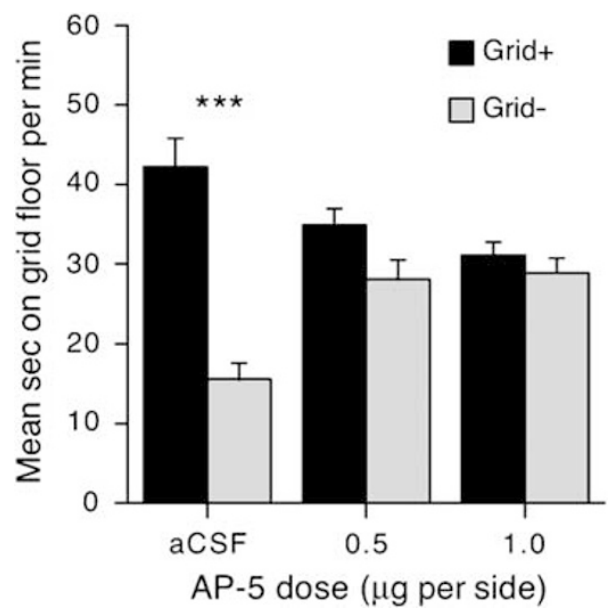

Figure 4 Infusions of AP-5 into the AcbC disrupted expression of ethanol CPP. Mean sec per min (+ SEM) spent on the grid floor during the 30 min of the test session. Grid + and Grid-conditioning subgroups n's are, respectively: aCSF $n=10$ and $13 ; 0.5 \mu \mathrm{g}$ per side $n=9$ and I2; $1.0 \mu \mathrm{g}$ per side $n=11$ and 8. Difference between conditioning subgroups Grid + and Grid-: **** $=$ Bonferroni-corrected p's $<0.001$.

\section{Locomotor Activity}

Group means and significant statistical comparisons for conditioning and test activity are shown in Table 2.

Conditioning activity. To simplify presentation, conditioning activity data were collapsed across trials to create single means for the CS + and CS-. As in previous experiments, ethanol induced large increases in locomotor activity on CS + trials (Cunningham et al, 2006b; Gremel and Cunningham, 2007). In experiment 1 , overall activity levels (combined CS + and CS - trials) were slightly higher in the $10 \mu \mathrm{g}$ per side group than in the $1 \mu \mathrm{g}$ per side group, reflecting a small sampling difference between dose groups (ie, there was no difference in experimental manipulations between the groups at this point). However, no group effects or interactions between group and trial type (CS + vs CS-) were seen in any of the other experiments, suggesting that 
Table 2 Locomotor Activity

\begin{tabular}{|c|c|c|c|c|c|}
\hline & $\begin{array}{c}\text { Dose } \\
(\mu \mathrm{g} \text { per side) }\end{array}$ & Final $n$ & $\begin{array}{c}\text { CS+ trials } \\
\text { counts/min } \pm \text { SEM }\end{array}$ & $\begin{array}{c}\text { CS }- \text { trials } \\
\text { counts/min } \pm \text { SEM }\end{array}$ & $\begin{array}{l}\text { Mean test activity } \\
\text { counts/min } \pm \text { SEM }\end{array}$ \\
\hline \multicolumn{6}{|l|}{ Experiment 1} \\
\hline \multirow{3}{*}{ Intra-AcbC Flupenthixol } & । & 9 & $178 \pm 5^{\mathrm{a}}$ & $63 \pm 4^{\mathrm{a}}$ & $34 \pm 3^{b}$ \\
\hline & 10 & 25 & $210 \pm 6$ & $79 \pm 3$ & $36 \pm 2^{c}$ \\
\hline & \multicolumn{5}{|c|}{ Trial type: $\mathrm{F}(\mathrm{I}, 105)=966.9 * * * *$} \\
\hline \multicolumn{6}{|l|}{ Experiment 2} \\
\hline \multirow[t]{2}{*}{ Intra-Amy flupenthixol } & aCSF & 31 & $177 \pm 4$ & $69 \pm 2$ & $39 \pm 2$ \\
\hline & 10 & 8 & $159 \pm 12$ & $66 \pm 6$ & $33 \pm 2$ \\
\hline \multicolumn{6}{|l|}{ Experiment 3} \\
\hline \multirow[t]{4}{*}{ Intra-AcbC AP-5 } & aCSF & 23 & $183 \pm 8$ & $69 \pm 2$ & $41 \pm 2$ \\
\hline & 0.5 & 21 & $189 \pm 8$ & $74 \pm 3$ & $51 \pm 3$ \\
\hline & 1.0 & 19 & $|9| \pm 11$ & $72 \pm 4$ & $74 \pm 6^{\mathrm{d}, \mathrm{e}}$ \\
\hline & & & \multicolumn{2}{|c|}{ Trial type: $F(1,60)=870.6 * * * *$} & Dose group: $F(2,60)=17.8 * * * *$ \\
\hline
\end{tabular}

${ }^{*} p<0.05,{ }^{*} * * * 0.001$ ( $p$-values for all group comparisons are Bonferroni-corrected).

${ }^{\mathrm{a}} \mathrm{\mu g}$ per side group activity means significantly different from $10 \mu \mathrm{g}$ per side group mean, $p<0.05$

bDifference from aCSF group, $p<0.05$.

'Difference from aCSF Group, $p<0.01$.

${ }^{\mathrm{D} D i f f e r e n c e ~ f r o m ~ a C S F ~ G r o u p, ~} p<0.001$.

${ }^{\mathrm{e}} \mathrm{l} .0 \mu \mathrm{g}$ per side group significantly different from $0.5 \mu \mathrm{g}$ per side group, $p<0.05$.

all groups within each experiment had similar activity responses during conditioning.

Test activity. D1/D2/D3-type receptor antagonism in the Acb decreased test activity levels (experiment 1). All flupenthixol-treated groups (1, 10, or $20 \mu \mathrm{g}$ per side) showed significantly lower levels of activity than aCSFinfused controls, but there were no differences among the flupenthixol groups. Similarly, intra-Amy flupenthixol $(20 \mu \mathrm{g}$ per side) significantly lowered test activity levels in comparison to aCSF (experiment 2). However, there were no differences between the aCSF and $10 \mu \mathrm{g}$ per side dose groups, or between the 10 and $20 \mu \mathrm{g}$ per side dose groups in experiment 2. In addition, $20 \mu \mathrm{g}$ per side flupenthixol reduced activity similarly in all three Amy subroups (BLA, $\mathrm{CE}$, Both; data not shown). In contrast, NMDA receptor antagonism in the Acb generally increased test activity levels (experiment 3). Infusions of the high AP-5 dose $(1.0 \mu \mathrm{g}$ per side) significantly increased activity levels compared to either the low AP- 5 dose $(0.5 \mu$ g per side) or aCSF. However, the aCSF and $0.5 \mu \mathrm{g}$ per side groups did not differ. There were no effects of replication on test activity levels in the aCSF groups in any of these experiments.

\section{DISCUSSION}

These are the first studies in any species to demonstrate involvement of dopamine D1/D2/D3 receptor activation within BLA and the first studies in mice to implicate Acb NMDA receptors in the expression of an ethanol-conditioned behavior (CPP). Moreover, these studies show that dopamine receptors within $\mathrm{CE}$ and Acb are not involved in the expression of such behavior. Although it is not known whether these effects reflect a decrease in the conditioned value of the cue, impaired retrieval of the cue-drug association, or a decrement in the learning or performance of the approach response, these studies offer important new information about the specific receptor systems within Amy and Acb that modulate behaviors controlled by an ethanolpaired cue.

\section{Ethanol CPP Expression does not Depend on Dopamine Activation in Acb}

Surprisingly, expression of ethanol-induced CPP in mice was not dependent upon D1/D2/D3-type receptor activation in Acb. This finding contrasts with previously reported dopamine antagonist effects on the reinforcing effect of ethanol in rats as indexed by operant SA procedures (Rassnick et al, 1992; Samson et al, 1993; Hodge et al, 1994) and by ethanol conditioned appetitive responding in an SA procedure (Czachowski et al, 2001, 2002; Samson and Chappell, 2004). A possible explanation may be that the target response in CPP (ie, approach towards the ethanolpaired cue) has never produced ethanol, whereas the target 
response in an SA procedure (eg, barpressing) has previously produced the primary reinforcer and may therefore depend upon intra-Acb dopamine transmission. However, it is also possible that there is a more fundamental species (ie, mouse vs rat) difference in the role played by Acb in the expression of ethanol-conditioned behaviors. This possibility is supported by a recent study in which an intra-AcbSh dopamine antagonist was reported to reduce expression of CPP induced by an intracerebroventricular ethanol injection in rats (Walker and Ettenberg, 2007), a finding that is at odds with our finding of no effect on ethanol CPP in mice. Thus, although Acb dopamine receptors may be involved in the expression of ethanol conditioned behaviors in rats (Samson and Chappell, 2004; Walker and Ettenberg, 2007), the current findings suggest that the previously hypothesized alterations in Acb dopamine receptor activation resulting from changes in VTA dopamine neuron activity do not contribute to expression of ethanol-induced CPP in mice (Bechtholt and Cunningham, 2005). It may be that the differing neural mechanisms between species reflect differences in the magnitude or direction of preference expressed between mice and rats (Tzschentke, 1999, 2007; Fidler et al, 2004).

\section{Ethanol CPP Expression Depends on Dopamine Activation in Amy}

These studies provide the first experimental evidence for the role of intra-Amy dopamine receptors in the expression of any ethanol-conditioned behavior in either rats or mice. Moreover, our data suggest that nuclei within the Amy play different roles in dopamine mediation of ethanol-conditioned behavior because CPP expression was blocked in mice that received flupenthixol infusions into BLA, but not in mice that were infused only into CE. Although several other receptors within $\mathrm{CE}$ have been implicated in the modulation of ethanol SA (eg, CRF: Funk et al, 2006; Funk and Koob, 2007; GABA $A_{A}$ : Hyytiä and Koob, 1995; Roberts et al, 1996; serotonin: Dyr and Kostowski, 1995) or ethanol CPP in rats (NMDA: Zhu et al, 2007), it does not yet appear that any ethanol SA study has shown a functional role for dopamine receptors within CE. Reports of increased FOS activation in the BLA in rats after exposure to a cue previously paired with ethanol (Zhao et al, 2006; Radwanska et al, 2007), as well as the observation of VTA dopamine projections to BLA in DBA/2J mice (Ford et al, 2006) lend support to our conclusion of intra-BLA dopamine receptor involvement in the modulation of ethanol conditioned behavior.

\section{NMDA Receptors in Acb Modulate Ethanol CPP Expression}

Although dopamine activation in Acb is not necessary, NMDA receptor activation within Acb appears to be critical for expression of ethanol CPP. Infusions of AP-5 aimed at AcbC blocked expression of ethanol CPP. Although the highest dose of AP-5 increased locomotor activation, which may complicate interpretation of CPP results (Gremel and Cunningham, 2007), the lowest dose was sufficient to block CPP expression without locomotor effects, eliminating nonspecific interpretations of this outcome. Our finding is in concordance with a previous study showing that NMDA antagonist infusion into Acb disrupted ethanol SA in rats (Rassnick et al, 1992). Moreover, expression of morphineinduced CPP in rats has also been found to depend on NMDA receptor activation in Acb (Popik and Kolasiewicz, 1999). While it has previously been shown that NMDA receptors within Acb mediate ethanol's physiological effects (Nie et al, 1994; Maldve et al, 2002), these are the first data demonstrating a functional role for intra-Acb NMDA receptors in ethanol-conditioned behavior in mice.

\section{Use of CPP to Examine Ethanol-Motivated Behaviors}

In contrast to other drugs of abuse, very little is known about the specific neural areas and mechanisms mediating associative control over cue-induced ethanol-seeking behavior. Many of the investigations into associative control over cue-induced psychostimulant-seeking behaviors have used self-administration procedures with second order schedules of reinforcement or acquisition of a new response (for review see Everitt and Robbins, 2005). Although a study using ethanol intragastric self-administration successfully demonstrated the ability of an ethanol-paired cue to act as a conditioned reinforcer (Smith et al, 1977), when attempted using oral ethanol self-administration, presentation of the previously ethanol-paired conditioned stimulus alone barely supported responding and only slightly attenuated extinction of responding (Slawecki et al, 1999). Further, a stimulus previously paired with oral ethanol self-administration was insufficient as a conditioned reinforcer, as increases in responding directed towards the stimulusproducing lever were only observed after intra-Acb infusions of amphetamine (Slawecki et al, 1997). Given the difficulty in employing an oral route of ethanol administration to measure acquisition of a new response or the ability of the conditioned stimulus to maintain responding, use of the CPP procedure provides an alternative means to assess associative processes controlling ethanol-seeking behaviors.

\section{Learning Processes Underlying CPP Expression}

In contrast to most ethanol SA procedures, the CPP procedure provides a way to investigate ethanol-conditioned behaviors in the absence of ethanol's direct effects. CPP also allows experimenters to measure an ethanol conditioned response that has never produced the primary reinforcer (ie, ethanol). Theoretically, Pavlovian conditioned approach behavior, conditioned reinforcement, and conditioned incentive may all be operating in CPP (Cunningham et al, 1995; Cunningham and Patel, 2007; Kumar, 1972; Swerdlow et al, 1989; Uslaner et al, 2006). While the Pavlovian relationship between the cue and ethanol itself is learned during the acquisition phase, the expression test provides an additional opportunity for learning as measured by approach and maintenance of contact with the cue previously paired with drug, without exposure to the drug. Because mice in our procedure are responding to tactile cues presented in the dark, it is difficult to explain CPP test performance simply in terms of Pavlovian conditioned approach to a distal CS 
(Cunningham et al, 2006b; Gremel and Cunningham, 2008), although this possibility cannot be completely dismissed.

Our finding that the Amy is importantly involved in ethanol CPP is generally consistent with a broader literature implicating Amy in the learning or expression of other conditioned appetitive behaviors (see reviews by: Holland and Gallagher, 1999; Everitt et al, 2003; Everitt and Robbins, 2005). For example, several studies have suggested that conditioned reinforcement is regulated by the BLA (Burns et al, 1993; Cador et al, 1989; Whitelaw et al, 1996), whereas CE modulates Pavlovian conditioned approach behavior (Parkinson et al, 2000). Although our previous lesion study demonstrated that expression of ethanol CPP was dependent upon an intact Amy (Gremel and Cunningham, 2008), the current findings suggest that activation of dopamine receptors specifically within BLA, not CE, is necessary for the behavior. The critical role played by BLA dopamine receptors is further corroborated by data showing that these receptors modulate cocaine-induced conditioned reinforcement on a second-order schedule in rats (Di Ciano and Everitt, 2004) and are necessary for the acquisition of responding for a previously sucrose-paired cue (Hitchott and Phillips, 1998). Given these previous findings, the present data suggest that conditioned reinforcement processes modulated by BLA dopamine receptors may be influencing expression of ethanol CPP induced by a tactile cue in mice.

Although previous findings have implicated Acb NMDA receptor involvement in the direct reinforcing properties of ethanol (Rassnick et al, 1992), the role NMDA receptors in the AcbC play in ethanol-conditioned behavior is less clear. For example, antagonism of intra-AcbC NMDA receptors with AP-5 had little effect on responding for a cocaineconditioned reinforcer (Di Ciano and Everitt, 2001) suggesting that Acb NMDA receptors are not critical for maintaining responding for a conditioned reinforcer. However, the first test session in our procedure does not model maintenance behavior, but instead acquisition of responding for the conditioned reinforcer. Additionally, intra-Acb NMDA antagonism impaired only the acquisition, not expression, of Pavlovian approach behavior (Di Ciano et al, 2001), suggesting that Pavlovian approach behaviors are not controlling the present test behavior. However, AcbC NMDA receptors have been implicated in responseoutcome learning (Kelley et al, 1997; Baldwin et al, 2000). This outcome may be consistent with our finding that blockade of Acb NMDA receptors reduced ethanol CPP expression during testing when mice first learn to approach the conditioned reinforcer, further suggesting that Acb NMDA receptors mediate initial learning and performance of a motivated response (Hernandez et al, 2005). Overall, these findings raise an interesting hypothesis about the processes underlying ethanol CPP. Perhaps during expression testing, intra-Acb NMDA receptors govern initial learning of BLA dopamine-mediated motivated responding for the conditioned reinforcer.

The Role of Acb and Amy Dopamine Receptors, and Acb NMDA Receptors in Locomotor Activity During Testing

Previous studies involving systemic administration of D1 and D2 antagonists (Dickinson et al, 2003) or dopamine receptor knockout mice (Holmes et al, 2004) have shown that dopamine receptor blockade or inactivation reduces locomotor activity. The present findings (Table 2) suggest that such activity reductions might reflect interference with dopamine signaling either in the Acb, Amy or both structures. Furthermore, intra-Acb NMDA receptors are implicated in the control of activity by our finding that AP- 5 increased activity, which is generally consistent with previous studies showing activity increases after systemic injection of a competitive NMDA antagonist (Boyce-Rustay and Cunningham, 2004).

Given these antagonist effects on general test activity, consideration must be given to the suggestion that antagonist effects on CPP were secondary to group differences in test activity, a possibility raised by recent data showing a negative correlation between test activity and expression of CPP (Gremel and Cunningham, 2007). However, several observations argue against an activitybased interpretation of our CPP data. First, the direction of the effect of intra-Amy dopamine antagonism on CPP in experiment 2 (ie, reduced CPP) was opposite to predictions based on the inverse relationship between activity and CPP. Second, as shown by the lack of CPP differences in experiment 1 , similar decreases in activity per se were not sufficient to alter CPP. Finally, although one might attribute the reduced preference seen at the highest AP-5 dose to increased test activity (Gremel and Cunningham, 2007), the reduced preference seen at the lowest AP- 5 dose $(0.5 \mu \mathrm{g}$ per side) cannot be explained by activity effects.

\section{Summary}

Our data show that expression of ethanol CPP in mice is mediated by dopamine receptors in Amy and by NMDA receptors in Acb. Moreover, within Amy, dopamine receptor activation within $\mathrm{BLA}$, but not $\mathrm{CE}$, modulated CPP expression. Surprisingly, dopamine receptor activation within Acb had no effect. Although several of these findings are consistent with previous findings in rats on mechanisms underlying other appetitive conditioned behaviors, our data on the role of Acb dopamine receptors in mouse CPP are at odds with operant ethanol SA and ethanol CPP findings in rats, raising the possibility of a species difference in the mechanisms underlying Acb's role in the expression of ethanol conditioned behaviors. Nevertheless, the similarity between the neural mechanisms involved in mouse ethanol CPP and those underlying conditioned reinforcement in rats encourages continued use of the CPP procedure to examine the learning and motivational processes underlying the acquisition, maintenance, and extinction of ethanolseeking behaviors.

\section{ACKNOWLEDGEMENTS}

This research was supported by NIH-NIAAA grants AA016041, AA007468, and AA007702. We thank Peter Groblewski and Charlene Voorhees for comments on an earlier draft of this paper. Experiments within this paper comply with the current laws of the United States of America. 


\section{DISCLOSURE/CONFLICT OF INTEREST}

The authors declare that there is no conflict of interest. CMG and CLC declare that, except for income received from their primary employer, no financial support or compensation has been received from any individual or corporate entity over the past 3 years for research or professional services and there are no personal financial holdings that could be perceived as constituting a potential conflict of interest.

\section{REFERENCES}

Baldwin AE, Holahan MR, Sadeghian K, Kelley AE (2000). $\mathrm{N}$-methyl-D-aspartate receptor-dependent plasticity within a distributed corticostriatal network mediates appetitive instrumental learning. Behav Neurosci 114: 84-98.

Bechtholt AJ, Cunningham CL (2005). Ethanol-induced conditioned place preference is expressed through a ventral tegmental area dependent mechanism. Behav Neurosci 119: 213-223.

Boyce-Rustay JM, Cunningham CL (2004). The role of NMDA receptor binding sites in ethanol place conditioning. Behavioral Neuroscience 118: 822-834.

Burns LH, Robbins TW, Everitt BJ (1993). Differential effects of excitotoxic lesions of the basolateral amygdala, ventral subiculum and medial prefrontal cortex on respond- ing with conditioned reinforcement and locomotor activity potentiated by intra-accumbens infusions of D-amphetamine. Behav Brain Res 55: 167-183.

Cador M, Robbins TW, Everitt BJ (1989). Involvement of the amygdala in stimulus-reward associations: interaction with the ventral striatum. Neuroscience 30: 77-86.

Corbit LH, Janak PH (2007). Ethanol-associated cues produce general pavlovian-instrumental transfer. Alcohol Clin Exp Res 31: 766-774.

Cunningham CL (1994). Modulation of ethanol reinforcement by conditioned hyperthermia. Psychopharmacology (Berl) 115: 79-85.

Cunningham CL (1998). Drug conditioning and drug-seeking behavior. In: O'Donohue W (ed). Learning and Behavior Therapy. Allyn and Bacon: Boston. pp 518-544.

Cunningham CL, Prather LK (1992). Conditioning trial duration affects ethanol-induced conditioned place preference in mice. Anim Learn Behav 20: 187-194.

Cunningham CL, Dickinson SD, Okorn DM (1995). Naloxone facilitates extinction but does not affect acquisition or expression of ethanol-induced conditioned place preference. Exp Clin Psychopharmacol 3: 330-343.

Cunningham CL, Ferree NK, Howard MA (2003). Apparatus bias and place conditioning with ethanol in mice. Psychopharmacology (Berl) 170: 409-422.

Cunningham CL, Gremel CM, Groblewski PA (2006a). Druginduced conditioned place preference and aversion in mice. Nat Protoc 1: 1662-1670.

Cunningham CL, Patel P (2007). Rapid induction of Pavlovian approach to an ethanol-paired visual cue in mice. Psychopharmacology 192: 231-241.

Cunningham CL, Patel P, Milner L (2006b). Spatial location is critical for conditioning place preference with visual but not tactile stimuli. Behav Neurosci 120: 1115-1132.

Czachowski CL, Chappell AM, Samson HH (2001). Effects of raclopride in the nucleus accumbens on ethanol seeking and consumption. Alcohol Clin Exp Res 25: 1431-1440.

Czachowski CL, Santini LA, Legg BH, Samson HH (2002). Separate measures of ethanol seeking and drinking in the rat: effects of remoxipride. Alcohol 28: 39-46.
Di Ciano P, Everitt BJ (2001). Dissociable effects of antagonism of NMDA and AMPA/KA receptors in the nucleus accumbens core and shell on cocaine-seeking behavior. J Neurosci 25: 341-360.

Di Ciano P, Everitt BJ (2004). Direct interactions between the basolateral amygdala and nucleus accumbens core underlie cocaine-seeking behavior by rats. J Neurosci 24: 7167-7173.

Di Ciano P, Cardinal RN, Cowell RA, Little SJ, Everitt BJ (2001). Differential involvement of NMDA, AMPA/kainate, and dopamine receptors in the nucleus accumbens core in the acquisition and performance of pavlovian approach behavior. J Neurosci 21: 9471-9477.

Dickinson SD, Lee EL, Rindal K, Cunningham CL (2003). Lack of effect of dopamine receptor blockade on expression of ethanolinduced conditioned place preference in mice. Psychopharmacology (Berl) 165: 238-244.

Dyr W, Kostowski W (1995). Evidence that the amygdala is involved in the inhibitory effects of 5-HT3 receptor antagonists on alcohol drinking in rats. Alcohol 12: 387-391.

Everitt BJ, Robbins TW (2005). Neural systems of reinforcement for drug addiction: from actions to habits to compulsion. Nat Neurosci 8: 1481-1489.

Everitt BJ, Cardinal RN, Parkinson JA, Robbins TW (2003). Appetitive behavior: impact of amygdala-dependent mechanisms of emotional learning. Ann N Y Acad Sci 985: 233-250.

Fidler TL, Bakner L, Cunningham CL (2004). Conditioned place aversion induced by intragastric administration of ethanol in rats. Pharmacol Biochem Behav 77: 731-743.

Ford CP, Mark GP, Williams JT (2006). Properties and opioid inhibition of mesolimbic dopamine neurons vary according to target location. J Neurosci 26: 2788-2797.

Funk CK, Koob GF (2007). A CRF(2) agonist administered into the central nucleus of the amygdala decreases ethanol self-administration in ethanol-dependent rats. Brain Res 1155: 172-178.

Funk CK, O'Dell LE, Crawford EF, Koob GF (2006). Corticotropinreleasing factor within the central nucleus of the amygdala mediates enhanced ethanol self-administration in withdrawn, ethanol-dependent rats. J Neurosci 26: 11324-11332.

Gremel CM, Cunningham CL (2007). Role of test activity in ethanol-induced disruption of place preference expression in mice. Psychopharmacology (Berl) 191: 195-202.

Gremel CM, Cunningham CL (2008). Roles of the nucleus accumbens and amygdala in the acquisition and expression of ethanol-conditioned behavior in mice. J Neurosci 28: 1076-1084.

Groenewegen HJ, Wright CI, Beijer AV (1996). The nucleus accumbens: gateway for limbic structures to reach the motor system? Prog Brain Res 107: 485-511.

Hernandez PJ, Andrzejewski ME, Sadeghian K, Panksepp JB, Kelly AE (2005). AMPA/kainite NMDA, and dopamine D1 receptor function in the nucleus accumbens core: a context-limited role in the encoding and consolidation of instrumental memory. Learn Mem 12: 285-295.

Heyser CJ, Roberts AJ, Schulteis G, Koob GF (1999). Central administration of an opiate antagonist decreases oral ethanol self-administration in rats. Alcohol Clin Exp Res 23: 1468-1476.

Hitchott PK, Phillips GD (1998). Double dissociation of the behavioral effects of $r(+)$ 7-oh-dpat infusions in the central and basolateral amygdala nuclei upon pavlovian and instrumental conditioned appetitive behaviors. Psychopharmacology (Berl) 140: $458-469$.

Hodge CW, Samson HH, Chappelle AM (1997). Alcohol selfadministration: further examination of the role of dopamine receptors in the nucleus accumbens. Alcohol Clin Exp Res 21: 1083-1091.

Hodge CW, Samson HH, Tolliver GA, Haraguchi M (1994). Effects of intraaccumbens injections of dopamine agonists and antagonists on sucrose and sucrose-ethanol reinforced responding. Pharmacol Biochem Behav 48: 141-150. 
Holland PC, Gallagher M (1999). Amygdala circuitry in attentional and representational processes. Trends Cogn Sci 3: 65-73.

Holmes A, Lachowicz JE, Sibley DR (2004). Phenotypic analysis of dopamine receptor knockout mice; recent insights into the functional specificity of dopamine receptor subtypes. Neuropharmacology 47: 1117-1134.

Hyytiä P, Koob GF (1995). GABAA receptor antagonism in the extended amygdala decreases ethanol self-administration in rats. Eur J Pharmacol 283: 151-159.

Kelley AE, Smith-Roe SL, Holahan MR (1997). Responsereinforcement learning is dependent on $N$-methyl-D-aspartate receptor activation in the nucleus accumbens core. Proc Natl Acad Sci USA 94: 12174-12179.

Krank MD (1989). Environmental signal for ethanol exposure enhance free-choice ethanol consumption. Behav Neurosci 103: 365-372.

Krank MD (2003). Pavlovian conditioning with ethanol: signtracking (autoshaping), conditioned incentive, and ethanol selfadministration. Alcohol Clin Exp Res 27: 1592-1598.

Kumar R (1972). Morphine dependence in rats: secondary reinforcement from environmental stimuli. Psychopharmacoligia 25: 332-338.

Maldve RE, Zhang TA, Ferrani-Kile K, Schreiber SS, Lippmann MJ, Snyder GL et al (2002). DARPP-32 and regulation of the ethanol sensitivity of NMDA receptors in the nucleus accumbens. Nat Neurosci 5: 641-648.

Nie Z, Madamba SG, Siggins GR (1994). Ethanol inhibits glutamatergic neurotransmission in nucleus accumbens neurons by multiple mechanisms. J Pharmacol Exp Ther 271: 1566-1573.

Parkinson JA, Willoughby PJ, Robbins TW, Everitt BJ (2000). Disconnection of the anterior cingulate cortex and nucleus accumbens core impairs Pavlovian approach behavior: further evidence for limbic cortical-ventral striatopallidal systems. Behav Neurosci 114: 42-63.

Paxinos G, Franklin KBJ (2001). The Mouse Brain in Stereotaxic Coordinates. Academic Press: San Diego.

Popik P, Kolasiewicz W (1999). Mesolimbic NMDA receptors are implicated in the expression of conditioned morphine reward. Naunyn Schmiedebergs Arch Pharmacol 359: 288-294.

Radwanska K, Wrobel E, Korkosz A, Rogowski A, Kostowski W, Bienkowski P et al (2007). Alcohol relapse induced by discrete cues activates components of AP-1 transcription factor and ERK pathway in the rat basolateral and central amygdala. Neuropsychopharmacology print copy in press (originally published online Sept. 122007 at www.acnp.org/citations/npp1301567/).

Rassnick S, Pulvirenti L, Koob GF (1992). Oral ethanol selfadministration in rats is reduced by the administration of dopamine and glutamate receptor antagonists into the nucleus accumbens. Psychopharmacology (Berl) 109: 92-98.

Robbins TW, Everitt BJ (2002). Limbic-striatal memory systems and drug addiction. Neurobiol Learn Mem 78: 625-636.

Roberts AJ, Cole M, Koob GF (1996). Intra-amygdala muscimol decreases operant ethanol self-administration in dependent rats. Alcohol Clin Exp Res 20: 1289-1298.

Samson HH, Chappell AM (2004). Effects of raclopride in the core of the nucleus accumbens on ethanol seeking and consumption: the use of extinction trials to measure seeking. Alcohol Clin Exp Res 28: 544-549.

Samson HH, Hodge CW, Tolliver GA, Haraguchi M (1993). Effect of dopamine agonists and antagonists on ethanol-reinforced behavior: the involvement of the nucleus accumbens. Brain Res Bull 30: 133-141.

Sesack SR, Deutch AY, Roth RH, Bunney BS (1989). Topographical organization of the efferent projections of the medial prefrontal cortex in the rat: an anterograde tract-tracing study with Phaseolus vulgaris leucoagglutinin. The Journal of comparative neurology 290: 213-242.

Sesack SR, Pickel VM (1990). In the rat medial nucleus accumbens, hippocampal and catecholaminergic terminals converge on spiny neurons and are in apposition to each other. Brain Research 527: 266-279.

Slawecki CJ, Samson HH, Chappell A (1997). Intranucleus accumbens amphetamine infusions enhance responding maintained by a stimulus complex paired with oral ethanol selfadministration. Pharmacol Biochem Behav 58: 1065-1073.

Slawecki CJ, Samson HH, Chappell A (1999). Presentation of an ethanol-paired stimulus complex alters response patterns during extinction. Pharmacol Biochem Behav 62: 127-135.

Smith SG, Werner TE, Davis WM (1977). Alchol-associated conditioned reinforcement. Psychopharmacology 53: 223-226.

Swanson LW (1982). The projections of the ventral tegmental area and adjacent regions: A combined fluorescent retrograde tracer and immunofluorescence study in the rat. Brain Research Bulletin 9: 321-353.

Swerdlow NR, Gilbert D, Koob GF (1989). Conditioned drug effects on spatial preference: critical evaluation. In: Boulton AA, Baker GB, Greenshaw AJ (eds). Psychopharmacology (Neuromethods Vol. 13). Humana Press: Clifton, NJ. pp 399-446.

Totterdell S, Smith AD (1989). Convergence of hippocampal and dopaminergic input onto identified neurons in the nucleus accumbens of the rat. Journal of Chemistry and Neuroanatomy 2: 285-298.

Tzschentke TM (1999). Measuring reward with the conditioned place preference paradigm: a comprehensive review of drug effects, recent progress and new issues. Prog Neurobiol 56: 613-672.

Tzschentke TM (2007). Measuring reward with the conditioned place preference (CPP) paradigm: update of the last decade. Addict Biol 12: 227-462.

Uslaner JM, Acerbo MJ, Jones SA, Robinson TE (2006). The attribution of incentive salience to a stimulus that signals an intravenous injection of cocaine. Behav Brain Res 169: 320-324.

Walker BM, Ettenberg A (2007). Intracerebroventricular ethanolinduced conditioned place preferences are prevented by fluphenazine infusions into the nucleus accumbens of rats. Behav Neurosci 121: 401-410.

Whitelaw RB, Markou A, Robbins TW, Everitt BJ (1996). Excitotoxic lesions of the basolateral amygdala impair the acquisition of cocaine-seeking behaviour under a second-order schedule of reinforcement. Psychopharmacology (Berl) 127: 213-224.

Zhao Y, Dayas CV, Aujla H, Baptista MA, Martin-Fardon R, Weiss F (2006). Activation of group II metabotropic glutamate receptors attenuates both stress and cue-induced ethanolseeking and modulates c-fos expression in the hippocampus and amygdala. J Neurosci 26: 9967-9974.

Zhu W, Bie B, Pan ZZ (2007). Involvement of non-NMDA glutamate receptors in central amygdala in synaptic actions of ethanol and ethanol-induced reward behavior. J Neurosci 27: 289-298. 